\title{
PROFESSIONAL RESPONSIBILITY AS A LAWYERING SKILL
}

\author{
Michael E. WOlfSON*
}

\section{INTRODUCTION}

For too long, the teaching of professional responsibility has generated dissatisfaction on the part of faculty and students alike. Complaints abound of dry and mechanical exploration of rules and cases and an emphasis on abstract philosophical concepts that lack the framework to establish a meaningful understanding of the pivotal role professional responsibility plays in the daily life of a lawyer. ${ }^{1}$ While the problems inherent in teaching the subject have long been recognized, little real progress has been made to move away from the traditional large class lecture/discussion teaching methodology still prevalent in the curriculum of many law schools. If anything approaching progress can be claimed, it is only in the recognition that traditional teaching methods do not adequately present the subject in a way that both stimulates and informs students, and allows them to assimilate the information and skills necessary for the ethical pursuit of a career in the law.

The solutions that have generally been proposed to deal with the problems surrounding the teaching of professional responsibility seem to fall into two basic categories. The first attempts to address the perception that the course lacks sufficient intellectual and doctrinal content to give it the kind of stature that other courses in the curriculum command. Without such stature, it is argued, neither students nor faculty will perceive professional responsibility as a subject that belongs at the core of a program to prepare students for their role as lawyers. In other words, if professional responsibility courses were structured to look and feel more like such core courses as Contracts, Torts, and Property, students and faculty would take the class more seriously than they currently do. ${ }^{2}$

\footnotetext{
Copyright $\odot 1996$ by Law and Contemporary Problems

* Professor of Law and Director of the Ethics Videotape Project funded by a grant from the W.M. Keck Foundation, Loyola Law School, Los Angeles, California.

1. James E. Moliterno, An Analysis of Ethics Teaching in Law Schools: Replacing Lost Benefits of the Apprentice System in the Academic Atmosphere, 60 U. Cin. L.R. 83 (1991); Deborah L. Rhode, Ethics by the Pervasive Method, 42 J. LEGAL EDUC. 31, 39-41 (1992).

2. Many professional responsibility texts are primarily casebooks whose emphasis on rules, statutes, and cases help shape the class in which they are used, causing such classes to look a good deal like other substantive courses. See, e.g., GeOFfreY C. HAZARD, JR., ET AL., THE LAW AND ETHICS OF LAWYERING (2d ed. 1994).
} 
The second approach to solving the problems inherent in teaching professional responsibility focuses primarily on selecting and using materials in the classroom that more realistically relate to the world in which the ethical principles of the profession are meant to function. ${ }^{3}$. Whether these materials are used in a class devoted entirely to professional responsibility or as part of a variety of substantive courses, ${ }^{4}$ the materials themselves are considered the solution to the problem of student and teacher dissatisfaction. The actual methods used to bring those materials to bear on the instructional dialogue, however, have not undergone the kind of change that would appear warranted by the inability of the subject matter to stimulate an appreciation for the degree of ethical behavior that the profession and the public demand.

While there has been some tinkering with the methods used to teach professional responsibility, little has been done to respond to the need to teach the subject in a way that provides students with more than a mere sampling of rules and principles. Professional responsibility courses exist to prepare students to make the kind of moral and ethical choices they will be confronted with in a world where the practice of law has changed from a profession to something far closer to a business. Only if students can experience the contextual framework for the kind of significant ethical dilemmas they will face in practice can the subject of professional responsibility rise to a level comparable to classes that students believe, sometimes wrongly, are central to their education and the conduct of their professional lives after law school.

It has been suggested that professional responsibility, unlike other subjects, infuses virtually every course a student takes with a set of ethical principles that will define the permissible limits within which the particular subject matter of a course will eventually be applied in practice. ${ }^{5}$ The so-called "pervasive method" for teaching ethics throughout the curriculum, while a nice idea, has remained a subject for academic debate, without significant practical implementation in the curriculum of most law schools. And even if the pervasive method were implemented, it would do little to convey to students the role ethical principles will play in the conduct of their professional lives. Whether the subject of professional responsibility is taught in a separate course or as part of a variety of courses, it generally remains today an abstract subject in which analysis and doctrinal discussion convey the impression that, in the world of lawyering, there is time for dispassionate reflection before ethical decisions need to be made. Since far too often nothing could be further from the truth, little has been achieved with this teaching approach other than an exploration of subject matter disconnected from reality. Such an exploration suggests that resolving ethical questions is simply a matter of interpreting rules in ways that

3. Richard A. Zitrin \& CARol M. Langford, Legal Ethics in the Practice of LAW 3 (1995).

4. The pervasive approach to teaching professional responsibility is discussed at length in Rhode, supra note 1 , at $50-56$.

5. Deborah L. Rhode \& David luban, Legal Ethics 1 (2d ed. 1995). 
wring whatever meaning from their language the student wishes. Issues of responsibility to clients, to courts, to third parties, and to the public are lost in the disembodied discussion of rules and principles, even when nudged toward reality by combining case law with the use of problem-solving exercises.

The effort to convince students and faculty of the pivotal importance of professional responsibility by casting the class in the image of so-called core courses has not yielded the kind of results the effort has sought to achieve. Professional Responsibility remains the step-child of law school curricula, ${ }^{6}$ retaining its status as a required course primarily because the American Bar Association ("ABA") accreditation standards impose such a required status on any school wishing to avail itself of ABA accreditation. " While the effort to select teaching materials that inject a semblance of reality into the learning experience has helped in the quest to stimulate a greater appreciation for the subject of ethics, it is only a halfway measure on the road to exposing students to an area of law that will pervade their entire legal careers.

II

\section{THE LOYOLA METHOD OF FULl INTEGRATION}

Over a decade ago, in an attempt to move beyond mere tinkering with the way professional responsibility is taught, Loyola Law School, Los Angeles, restructured the way it taught the subject by creating a class that fully integrated ethics and lawyering skills into a single required course.

\section{A. Specifics of the Course}

Since 1984, every student at Loyola has been required to take a course that explores the related subjects of client interviewing, client counseling, and legal negotiation, as well as the subject of professional responsibility. ${ }^{8}$ The decision to combine these subjects resulted from the simple observation that most ethical issues arise in the context of the representation of a client, and that, while some ethical issues could potentially be anticipated, many arise unexpectedly, much as evidentiary issues arise at trial. ${ }^{9}$ Unless students acquire a sensitivity to a wide range of underlying ethical rules and principles, they may fail to recognize

6. Rhode, supra note 1, at 40 (citing Dale C. Moss, Out of Balance: Why Can't Law Schools Teach Ethics?, STUDENT LAW., Oct. 1991, at 19).

7. Standard 302(a)(iv) of the ABA Standards for the Accreditation of Law Schools mandates that all students take instruction in professional responsibility.

8. The course is titled Ethics, Counseling, and Negotiation. It is a four-unit, single semester class that meets twice per week, and it must be taken during the students' second year. This requirement allows students to build on knowledge gained in their first-year classes by having them apply the substantive law of torts, contracts, property, and criminal law to the client-oriented simulations used to teach lawyering skills and professional responsibility.

9. Some law schools teach Evidence in combination or close association with Trial Advocacy in order to give students a contextual framework in which to learn the substantive law of evidence. For example, Temple University School of Law offers a year-long, ten-unit class that integrates the teaching of evidence, trial advocacy, and professional responsibility. 
and deal with an issue when it initially arises. Like a missed objection at trial, the damage is done when a failure to recognize an ethical issue prevents a lawyer from addressing it at the moment of its inception. And the damage done is not only to the client's interests, but to those of the lawyer as well.

The decision to combine ethics with lawyering skills also recognized that if the contextual framework for the conduct of a lawyer's professional activities is omitted from the approach used to teach ethics, the course becomes another law school class devoted to extended discussion of doctrine, rules, and interpretive opinions. The student moves through the usual cycle of reading assignments followed by extended class discussion conveying the impression that, like other problems brought to a lawyer by a client, professional responsibility is a subject that can be considered at length in an atmosphere of intellectual rigor and objective analysis. While such an approach to resolving ethical questions is certainly preferable, there is often in practice neither the time nor the absence of personal involvement necessary for leisurely objective analysis. Teaching the subject without the perspective students will confront in reality is like teaching trial advocacy solely by the lecture method, or training medical students without exposing them to patients. The introduction of the contextual framework not only infuses the learning experience with a healthy dose of reality, but also gives the subject matter an immediacy and importance that it lacks in the rarefied academic environment of traditional classroom presentations.

Loyola's combined Ethics/Lawyering Skills course is structured in a way that fully integrates both skills and professional responsibility throughout the course. The emphasis is continually on the interconnection between ethics and the skills necessary to deal effectively with a client and the reason a client is in need of legal services. The course begins with a general discussion of the lawyer's role in society and the relationship between a lawyer's personal values and his or her responsibilities as a legal professional. It then addresses potential ethical issues inherent in the initial formation of the lawyer-client relationship, such as advertising and solicitation, competency, communication, confidentiality, fees, and obligations regarding the need to represent unpopular or indigent clients. Having explored these areas primarily through problem-solving, the course proceeds to the subject of client interviewing, particularly initial client interviews. The skill of interviewing is explored using both live and video simulation materials. Ethical issues involving the areas already explored in class are liberally sprinkled throughout the exercises, and students must handle them as they would in the real world. It is one thing to analyze an assigned problem from the comfortable perspective of a homework assignment, but quite another to face the issue across a desk from a client. Students initially tend to find the experience difficult and a bit frightening, but, with repeated exposure to the contextual framework offered by simulating the environment of law practice, they come to appreciate the pivotal role the rules of professional responsibility play in virtually every aspect of a lawyer's professional life. The experience also 
reinforces the notion that ethical rules must be understood to a degree that allows a lawyer on a virtually instantaneous basis, to recognize the existence of potential ethical issues and to prevent those issues from being "resolved" through inadvertent inaction. Much as in the trial context where evidentiary objections are concerned, a lawyer must have a sufficient grasp of the rules of professional responsibility to make the kinds of decisions that often arise with little or no warning and require immediate attention.

After the interviewing segment of the class is completed, the course shifts to ethical issues that might arise during the representation itself and covers such areas as conflicts, withdrawal, the roles of the client and the lawyer in the decisionmaking process, the relationship of partners and associates while engaged in representing a client, communication, and confidentiality. This is followed by an exploration of the client-counseling process, in which the student observes and participates in a series of simulated and live exercises that are well-laced with related ethical issues. This same approach is used to explore resolution of a client's problem through negotiation, where students not only engage in extended exercises, but also confront a variety of ethical issues in the process.

The key to the ultimate effectiveness of the course has been the full integration of both skills and ethics throughout the class so that students quickly move from more traditional methods of examining ethical rules and principles to the use of that knowledge in the context of actual lawyer/client and lawyer/lawyer interactions. While the two ends of the process-traditional exploration of substantive material and live exposure to the lawyering environment-offer few teaching problems, the middle ground of quickly and effectively transitioning students from traditional study methods to full and immediate use of newly acquired knowledge presents the greatest challenge. It is in this area that the W.M. Keck Foundation's grant to Loyola Law School was focused.

As those who teach professional responsibility are well aware, materials that effectively simulate ethical issues in a real-world environment are few in number and often model a world in which most issues are far too obvious and, for students raised on television, about as realistic as an old-fashioned melodrama. While many Professional Responsibility instructors have taken to taping segments from popular television shows to pique student interest, the representations these segments present are often seriously distorted, predicated as they are on the need to entertain. To remedy these problems, Loyola produced two videotapes entitled "Professional Responsibility in Practice" to assist students in making the transition from the study of ethical rules to the application of those rules in the realistic environment of law practice. ${ }^{10}$ One

10. The videotapes are used to give students the opportunity to apply ethical rules and principles on a realistic, real-time basis. Shown in class with little or no advance warning of the issues that might arise, students are asked, at strategic points in the videotape, to discuss the actual and potential ethical issues, how they could or should be handled, and whether the lawyers in the videos addressed the issues 
of the videotapes depicts activities in a civil case and the other depicts activities in a criminal case. The preparation and production of both simulations utilized an advisory committee made up of legal and educational professionals, whose goal was to make each video as true to the reality of the lawyering experience as possible. The issues presented in the videos are often far from obvious, arising as they do when a lawyer is faced with a variety of competing business and professional pressures. The need to resolve what appears to be more pressing legal matters often masks the importance of identifying and dealing with potential ethical issues. Every effort has been made to realistically depict the legal environment in order to demonstrate the need for both a mastery of the principles of professional responsibility and constant vigilance in applying those principles on an immediate basis. Without such a recognition, students will not understand the critical role professional responsibility plays in the working life of a lawyer and will remain unconvinced that ethics is a subject that stands at the very core of their professional training.

\section{B. An Illustration From the Videotape Materials}

An example from one of the videotapes illustrates how an appreciation for the role professional responsibility plays in practice can be fostered while helping students make the transition from the study of rules and principles to the application of those rules in practice. The video, which focuses on a civil matter, begins with three investors coming to a lawyer to discuss ways in which to structure their relationship to not only achieve their investment goals, but also protect their financial interests. The investment they wish to make involves purchasing a small seaside hotel and renovating it to become a profitable resort. They agree on a corporate form, and the investment is undertaken. Three years later, the investment is apparently successful and the lawyer has been asked to come to the hotel ostensibly to discuss a workers' compensation matter. Before the investor who manages the resort on a day-to-day basis is ready to discuss the problem for which the lawyer was summoned, he enthusiastically leads the lawyer on a tour of the property, showing off what the investors have accomplished and describing what they hope to accomplish in the future.

The conversation is amiable, informal, and appears purely social in nature. The workers' compensation matter is raised only after the tour is completed. Some time after the meeting, a serious legal problem arises for which the tour and amiable social conversation become a significant factor. The content of that conversation and the relationship between the lawyer and the managing investor raise the specter that the lawyer may have breached a number of ethical responsibilities by failing to recognize and confront potentially significant legal issues hinted at by the managing investor during the tour of the resort. The point to be made for students, besides providing them an opportunity to analyze the potential legal and ethical issues involved, is that regardless of the nature 
of an interaction, a lawyer's duties and responsibilities can potentially extend to every contact with a client, regardless of its apparent context. The revelation that the conversation between the lawyer and the managing investor before the worker's compensation problem was addressed could be classified as a lawyer/client consultation, effectively illustrates the ongoing nature of a lawyer's ethical responsibilities to a client.

\section{Faculty and Student Reaction}

The course has received a mixed reaction over the twelve years it has been taught as a staple of Loyola's curriculum. Traditional faculty often express suspicion of the class since it teaches substantive materials in what might be considered an unorthodox way. To some degree, this suspicion is imparted to students, who quickly come to believe that unless a course looks and feels like more traditional law school classes, it cannot be of importance to their legal training. In addition, students are uncomfortable when they first approach the course because it requires them to deal with mock clients in a pressure-filled environment where ethical issues can arise unexpectedly, the client interaction is infused with all the limitations inherent in human communication, the time available to deal with the client's problem is limited, and the entire process is subject to the reward or detriment of a grade. In other words, a modeling of the life students have come to law school to prepare for. Even with all the suspicion and reluctance, though, the educational experience offered by the course is usually eye-opening for the students and gratifying for the instructor.

Experience demonstrates that, in their live simulations, students initially focus on a client's legal problems to the exclusion of all else, a clear by-product of the issue-spotting nature of legal education. However, after brief exposure to the simulated environment of law practice, students quickly come to appreciate the way ethical dilemmas pervade every aspect of their role as lawyers. Students then recognize that without a thorough grounding in basic ethical principles and vigilance throughout the process of representing a client, ethical decisions will be made for them by the forces of circumstance. This is particularly true when ethical issues are masked by the students' overriding desire to identify and resolve the clients' legal problems. Once students recognize the pervasiveness of the ethical component of representing a client, they begin to try to anticipate ethical issues based on the nature and circumstances surrounding the particular representation they have been asked to undertake. As the representation unfolds, they also begin to look for signals that might alert them to unanticipated ethical issues. Through such contextual simulations, students come to appreciate a dimension of lawyering that does not fully emerge from more traditional methods of teaching professional responsibility. 


\section{III}

\section{CONCLUSION}

In 1995, Loyola Law School retained the RAND Corporation to survey its graduates on the effectiveness of the combined Ethics/Lawyering Skills course now that the graduates had been in practice for a number of years. One of the questions contained in the survey asked whether the teaching of ethics would be better served by separating professional responsibility from the lawyering skills aspects of the course. Nearly two-thirds of all respondents to the survey indicated that maintaining integration of the skills and professional responsibility components was preferable.

Teaching professional responsibility as a lawyering skill is clearly a departure from generally accepted academic practice. But experience has shown that its effectiveness in stimulating student interest in and concern for the ethical dilemmas that confront lawyers on a daily basis makes such a departure worthwhile. 